\title{
Editors note: Journal of Gerontology \& Geriatrics Research
}

\section{Vasudev Ballal*}

Department of Conservative Dentistry and Endodontics, Manipal College of Dental Sciences, Manipal University, Manipal, Karnataka, India

*Corresponding editor: Vasudev Ballal, Manipal College of Dental Sciences, Manipal University, Karnataka, India, Tel: +91 9880626167; Fax: 90-0820-2570061; Email: drballal@yahoo.com

Rec date: Sep 12, 2016; Acc date: Sep 12, 2016; Pub date: Sep 14, 2016

Copyright: (c) 2016 Ballal V, et al. This is an open-access article distributed under the terms of the Creative Commons Attribution License, which permits unrestricted use, distribution, and reproduction in any medium, provided the original author and source are credited.

Citation: Ballal V (2016) Editors note: Journal of Gerontology \& Geriatrics Research. J Gerontol Geriatr Res 5: e138. doi:10.4172/2167-7182.1000e138

\section{Editorial Note}

Conveyance of Mentally Ill Person from their Property: Which Legislation to Use? - Mental Capacity Act (MCA) or Mental Health Act (MHA) or Court of Protection

The literature review appraised by Khan $\mathrm{F}$ and Chithiramohan $\mathrm{A}$, Alrightly addressed the commonly intrigued query regarding the conveyance of mentally ill person from their property. This review states the issues regarding the patient/ persons who are unable to take critical decisions regarding their health due to mental instability. It also elaborates the legal aspects as per the Mental Capacity Act or Mental Health Act or Court of protection on such perplexing concerns. The authors have also elaborated on issues concerned with guardianship order. In case of refusal/resistance by the patient to move to their accommodation facilitated by the concerned care-taker, the court of protection have the rights to convey the patient from home to their new accommodation.

\section{Assessment of the Effect of Information Access on Emotional Well-Being of the Elderly in Ibadan}

Oyinlola and Folaranmi conducted a descriptive research survey to assess the effect of information access on emotional well-being among the elderly visiting the Geriatric Center at the University College Hospital, Ibadan. According to the authors media plays a wide role in conveying information to the public especially the elderly. Their analysis indicated that among the communication tools, audio-visuals contributed the most to their emotional well-being, followed by printed articles and finally the internet usage. The authors have also put forward suggestions which include training of geriatric medical social workers, physicians in a socially delicate environment which could help in improvement of dignity of elderly patients visiting the hospitals.

\section{Accelerated Medical Education: Impact of a 48 Hour Hospice Home Immersion}

This manuscript authored by Tobarran et al, focused on models that were designed to learn about the palliative and end of life care for older adults. It was planned and implemented by the UNECOM Director of Geriatrics Education and Research. The study was performed by medical students who were given the opportunity to live in a hospice home, so has to get exposure to quality of care for patients in the end of life. The students worked with inter-professional team and learnt to provide family and post-mortem care. The authors concluded that such innovate practices during medical education will help the future clinicians to take proper decisions in life altering situations and also improve their competency in the profession.

\section{Cross Cultural Cohort Studies May Improve Understanding of Contributory Factors to Ageing Well}

This rapid communication describes a biopsychosocial pattern of aging among different cultures and ethnic races. The authors Yu $\mathrm{R}$ and Woo J, have compared the characteristics of inhabitants born in the year 1921 from places like Hong Kong, China, UK. The observations of the study exhibited that the people of Hong Kong had lower prevalence of systemic conditions unlike people of other countries however they rated their health as just moderate. This was attributed to the inadequacy in health literacy regarding aging process and the health system.

\section{An Elderly Primary Hyperaldosteronism Case with Atypical Presentation}

Cinar E, et al reported a unique case of hyperaldosteronism, which is one of the most common causes of secondary hypertension. This condition was diagnosed in a patient with recurrent photocoagulations due to retinopathy. 